\title{
Stable trophic structure across coastal nekton assemblages despite high species turnover
}

\author{
Sébastien Villéger ${ }^{1, *}$, Julia Ramos Miranda ${ }^{2}$, Domingo Flores Hernandez ${ }^{2}$, \\ Atahualpa Sosa Lopez ${ }^{2}$, David Mouillot ${ }^{1}$
}

${ }^{1}$ UMR CNRS-IFREMER-UM2 5119 Écosystèmes Lagunaires, Université Montpellier 2, CC 093, Montpellier 34095 Cedex 5 , France

${ }^{2}$ Centro de Ecología, Pesquerías y Oceanografía de Golfo de México (EPOMEX), Universidad Autónoma de Campeche, Av. Agustín Melgar s/n, Campeche 24030, Mexico

\begin{abstract}
The finding of invariant structures in species assemblages is of primary importance for ecology because it would suggest that, despite species turnover and environmental gradients, some self-organizing principles may shape these assemblages. Tropical estuarine and coastal ecosystems are ideal for investigating patterns in trophic structures because they contain many species and are characterized by a high variability for both biotic and abiotic variables. We used the data from a $150 \mathrm{~km}$ long transect in the Terminos Lagoon region (Campeche State, Mexico) where 37 stations were sampled monthly during $1 \mathrm{yr}$ for both abiotic parameters and nektonic assemblages. We then quantified 3 complementary components of trophic diversity (trophic richness, trophic evenness and trophic divergence) and then challenged the idea that some stable structures may emerge. We found that abiotic parameters, space and time have weak explanatory power on trophic diversity indices. We also observed a high species turnover both at local and regional scales, but it was unrelated to the small variations of trophic diversity indices. This stability of trophic structure is partly due to the predominance of the trophic class 3.25 to 3.5, which accounted invariably for between 50 and $60 \%$ of the total nekton biomass across space and time. These findings suggest that the species turnover observed in our system is not random but, rather, allows maintenance of the same abundance distribution along the trophic axis. The mechanisms underlying these emergent properties of trophic structures deserve to be investigated through the use of trophodynamic models.
\end{abstract}

KEY WORDS: Trophic diversity · Trophic level · Environmental gradients $\cdot$ Terminos Lagoon · Gulf of Mexico

\section{INTRODUCTION}

Despite the extraordinary complexity of natural systems, some ecologists expect that a few relatively simple laws may govern patterns such as the structure of species assemblages (Hubbell 2001). Uncovering general and repeatable patterns in species assemblages over space and time has been a major focus of research in ecology because identification of such patterns would suggest that apparently diverse and idiosyncratic assemblages may have common principles. Ultimately, the goal of such a comparative approach should be to identify the processes underpinning any observed universal pattern, which in turn would provide crucial knowledge allowing advances in conservation and environmental management (Mouillot 2007).

Trophic ecology has become a fertile area for discussion of intriguing regularities in assemblages of interacting species feeding on each other. After many contradictory investigations about the scale-invariance of trophic chain length, predator/prey ratio and connectance (relative density of links) in food webs (Briand \& Cohen 1984, Sugihara et al. 1989, Havens 
1992, Martinez 1992), there has been an emerging consensus about the scale dependence of these trophic structures (Martinez 1994, Deb 1995, Bersier \& Sugihara 1997, Bersier et al. 1999). However, the repeatability or the stability of trophic structures over space and time at the same scale of observation is still questionable. Moreover, the trophic structure of an assemblage cannot be fully captured by a single number (such as the connectance or the trophic chain length), and many facets of this structure, including species abundances and the distribution of biomass along trophic levels, have been overlooked due to a lack of adequate descriptors. Thus, the knowledge of the trophic structure of ecological assemblages is still incomplete, and the spatiotemporal stability in these structures remains unexplored. In the present study, using complementary trophic diversity indices, we sought ubiquity in the trophic structure of nekton assemblages in the Terminos Lagoon region (southern Gulf of Mexico) despite high environmental and species turnover.

Coastal lagoon ecosystems are of primary concern for human population welfare because they provide various services of high value (protein source, regulation of pollution and recreational areas), while anthropogenic activities severely impact them (Costanza et al. 1997). Fluctuating environmental conditions on short spatial and temporal scales also mark these ecosystems. This fluctuation is the consequence of low inertia to external events due to shallowness of water masses coupled with an interface position between marine and freshwater bodies (Basset et al. 2006). These ecological systems provide unique opportunities to investigate invariant patterns in the structure of assemblages because the high variability in environmental conditions generates a high species turnover across space and time (e.g. Wagner 1999). In these coastal systems, the nekton, including shrimps, fish, crabs and squids, is a major biological component. These macroorganisms have a large range of life-history traits, migratory behaviors and diets, thus occupying a key position in the flux of matter through space and time (e.g. Holmlund \& Hammer 1999). Identifying regularities in the structure of nekton assemblages in such ecosystems could be challenging because it would suggest the predominance of trophic-based processes despite high turnover in species identity and environmental conditions.

The vertical diversity of the food web is a component of biodiversity and plays a role in the productivity and stability of ecosystems (Diaz et al. 2006, Duffy et al. 2007). However, no consensus has emerged about correct estimations of an assemblage's vertical food web diversity, which we designate as 'trophic diversity.' Similarly to functional diversity, trophic diversity can- not be summarized using a single number. Therefore, we chose to estimate various facets of nekton assemblage trophic diversity using the framework of Mason et al. (2005), who defined 3 primary components of diversity (richness, evenness and divergence) with corresponding indices. These indices were based on the trophic level index which is an integrative parameter based on food items and diet composition and thus characterizes the position of species along the trophic chain. Trophic level is available for a great number of nektonic species across taxa, allowing inclusion of all species in studies of taxonomically and functionally heterogeneous assemblages. In addition, trophic level is a key parameter for modeling marine ecosystem functioning (Pauly et al. 2000, Gascuel 2005) or for studying fishery dynamics (Pauly et al. 1998, Pauly \& Watson 2005). For instance, the mean trophic level of fishery landings (MTI, Marine Trophic Index) was a relevant indicator demonstrating that we have been 'fishing down marine food webs' (Pauly et al. 1998). However, the mean trophic level refers only to the central position in the distribution of biomass along the trophic chain; in the study of Pauly et al. (1998), the variability of the biomass distribution along this trophic chain was not included. Therefore, the purpose of the present study is to quantify biomass distribution along the trophic axis by introducing a new set of trophic diversity indices: trophic richness, trophic evenness and trophic divergence.

As an application, we estimated these indices for the nekton assemblages of the Terminos Lagoon region and investigated their variations. In particular, we analyzed how trophic diversity varies with environmental conditions and through space and time. Then we tested the ubiquity of the trophic structure in relation to species turnover and at 2 scales of observation (local to regional).

\section{MATERIALS AND METHODS}

Study area. The study area is located along the southern coast of the Campeche State (Mexico) (Fig. 1). The Terminos Lagoon, which is $70 \mathrm{~km}$ long and $30 \mathrm{~km}$ wide, highly influences this part of the Gulf of Mexico. This wetland ecosystem is of ecological interest for flora and fauna and for terrestrial and aquatic biota. Several anthropogenic factors have affected it in past decades, including the development of intensive farming with concurrent deforestation of mangroves, intensive shrimp fishing, offshore oil extraction and the urbanization of Carmen Island (Ramos Miranda et al. 2005a). Moreover, previous studies have identified a shift from hypohaline to euhaline/hyperhaline conditions in the lagoon (salinity has been 


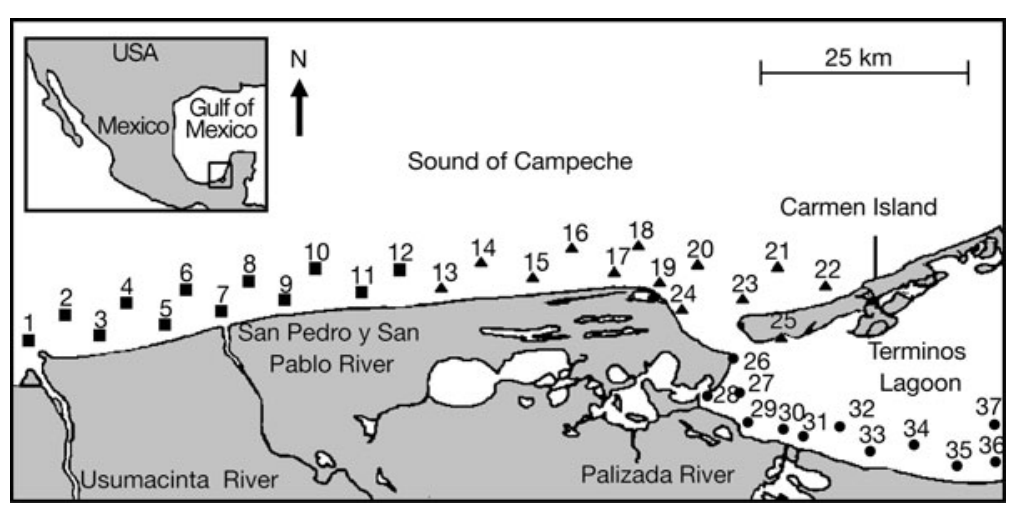

Fig. 1. Study area and 37 sampled stations. Symbols indicating each station depend on the spatial group to which the station belongs (see Fig. 3): (

Coast 1, («) Coast 2 and (•) Lagoon

increasing from 24.67 PSU in the 1980s to 26.8 PSU at the end of the 1990s) combined with a decreasing water depth (Ramos-Miranda et al. 2005b, Sosa-López et al. 2005).

The present study focuses on a $150 \mathrm{~km}$ long transect $\left(18^{\circ} 37^{\prime} 16^{\prime \prime} \mathrm{N}, 92^{\circ} 42^{\prime} 28^{\prime \prime} \mathrm{W}\right.$ to $18^{\circ} 30^{\prime} 20^{\prime \prime} \mathrm{N}$, $91^{\circ} 28^{\prime} 03^{\prime \prime} \mathrm{W}$ ) including 37 stations distributed in the southwestern part of the Terminos Lagoon and along the adjacent coast (Fig. 1). This transect crosses the discharge of 3 main rivers (the Usumacinta, San Pedro y San Pablo and Palizada rivers) and the Carmen inlet, the exit of the Terminos Lagoon flow (David \& Kjerfve 1998).

Sampling protocol. We conducted a monthly biological survey of the 37 stations from February 2003 to January 2004 (Fig. 1), locating sampling points using a Global Positioning System with a precision of $75 \mathrm{~m}$. The survey included both abiotic and biotic parameters. We recorded environmental variables such as water temperature, salinity, $\mathrm{pH}$ and dissolved oxygen for the top and bottom of the water column using Hydrolab HL 2011 equipment. Additionally, we measured depth and water transparency using a Secchi disk.

Nektonic assemblages were sampled using a shrimp trawl (length: $5 \mathrm{~m}$, mouth opening diameter: $2.5 \mathrm{~m}$, mesh size: $19 \mathrm{~mm}$ ) towed 12 min at a constant speed of 2.5 knots. The volume sampled was thus $4500 \mathrm{~m}^{3}$. Individual organisms were kept in ice on the boat before being frozen. For each sample, all individuals were identified to the species level using the keys of Fischer (1978), Castro-Aguirre (1978) and Resendez Medina $(1981 \mathrm{a}, \mathrm{b})$, and weighed to the nearest dg.

For each fish species, the trophic level index value $(T L)$ was recorded according to FishBase (Froese \& Pauly 2006). For invertebrates (shrimps, crabs, mantis shrimp and squids), we used the trophic level recorded in FishBase (Froese \& Pauly 2000) at the best taxonomic level available.
Trophic diversity indices. Functional diversity could be seen as the distribution of functional trait values and of abundance among entities in a given space, entities being either species at the community level or individuals at the population level. In the present study, we focused on the nekton trophic diversity by considering the trophic level as a functional trait. Following Grime (1998), who proposed the biomass ratio effect, we chose biomass as the most relevant measure for abundance; therefore, trophic diversity could be seen as the distribution of biomass along the trophic level axis (Fig. 2). As with species biodiversity, which can be split into different facets (e.g. species richness and evenness, Purvis \& Hector 2000), functional diversity was split into 3 complementary components (Mason et al. 2005): richness, evenness and divergence. We applied these 3 components to the distribution of abundance along a trophic axis to obtain a measure of trophic richness, trophic evenness and trophic divergence.

Trophic richness represents the proportion of the trophic chain an assemblage fills. It could be estimated by either the number of trophic levels (trophic richness sensu stricto) or the maximum range of trophic levels (length of the trophic chain) present in a nekton assemblage (Fig. 2). These 2 indices are complementary and potentially unrelated. For instance, the range can be high with the presence of only 2 extreme trophic levels (1 at each side of the trophic chain), whereas an assemblage with many species having close trophic levels will show a relatively small range.

Trophic evenness describes how equitably distributed the biomass is along the trophic axis. It includes both the regularity of the distribution of values along the trophic axis and the evenness of the abundance among these trophic levels. The functional regularity index (FRO) proposed by Mouillot et al. (2005) includes these 2 aspects. In the present study, we used a standardized version of the proposed index: for an assemblage of $S$ species, $T L$ and corresponding biomass $(w)$ were ranked increasingly to compute $S-1$ weighted evenness differences (EW) for species $i$ and $j$ using:

$$
\mathrm{EW}_{l}=\frac{T L_{i}-T L_{j}}{W_{i}+W_{j}}
$$

where 1 represents the $S-1$ pairs of species. These values were then standardized to a percentage weighted evenness:

$$
\mathrm{PEW}_{l}=\frac{\mathrm{EW}_{l}}{\sum_{l=1}^{S-1} \mathrm{EW}_{l}}
$$




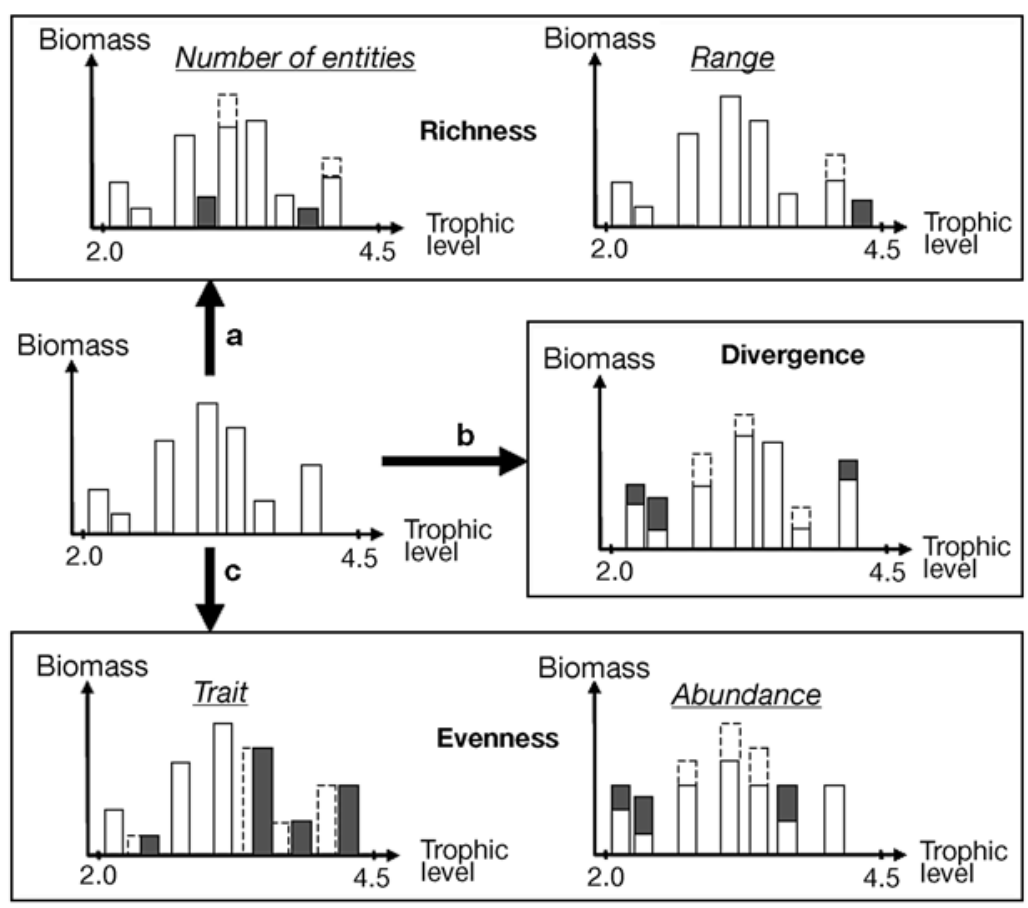

Fig. 2. Theoretical presentation of trophic diversity components. From a hypothetical assemblage, an increase of each trophic diversity component is illustrated in 3 directions: (a) increase in trophic richness with either an increase in the number of entities (left) or an increase in the range of trophic level values (right); (b) increase in trophic divergence due to a shift of biomass from the middle of the trophic axis to extremities; or (c) an increase in trophic evenness with either an increase in the regularity of the distribution of the trophic level values along the axis (left) or an increase in the regularity of biomass among these trophic level values (right)

In the case of perfect regularity of abundance distribution along the trophic axis, all $\mathrm{EW}_{1}$ would be equal and all $\mathrm{PEW}_{l}$ values would be $(S-1)^{-1}$. Conversely, when $\mathrm{PEW}_{l}$ values differ, trophic evenness must decrease. To this aim we compared $\mathrm{PEW}_{1}$ values to $(S-1)^{-1}$ to obtain the FRO index:

$$
\mathrm{FRO}=\frac{\sum_{l=1}^{S-1} \min \left(\mathrm{PEW}_{1}, \frac{1}{S-1}\right)-\frac{1}{S-1}}{1-\frac{1}{S-1}}
$$

This index is designed to be independent of the trophic richness and is constrained between 0 and 1 . The value 1 is obtained when all $\mathrm{PEW}_{l}$ are equal to $(S-1)^{-1}$. Trophic evenness of a community would be high if coexisting species have regularly spaced trophic levels with similar biomass (Fig. 2).

Trophic divergence quantifies the divergence of the nekton biomass distribution from the mean trophic level of the assemblage (Fig. 2). It is therefore correlated with niche differentiation and may indicate the potential resource use spectrum and intensity of competition. For example, with a maximum biomass near the mean trophic level value, trophic divergence would be low. Conversely, trophic divergence would be high if biomass density peaks at the extremities of the trophic axis. We estimated trophic divergence with the $\mathrm{FD}_{\text {var }}$ index of Mason et al. (2003). $F D_{\text {var }}$ is based on an abundance-weighted sum of squares analogous to a log-transformed variance:

$$
\begin{gathered}
\mathrm{FD}_{\mathrm{var}}=\frac{2}{\Pi} \arctan (5 V), \\
\text { with } \quad V=\sum_{i=1}^{S} w_{i} \times\left(\ln T L_{i}-\overline{\ln T L}\right)
\end{gathered}
$$

where $\overline{\ln T L}=\sum_{i=1}^{S} w_{i} \times \ln T L_{i}$

By design, $F D_{\text {var }}$ is independent of species richness and constrained to the 0 to 1 range.

Statistical properties of the indices were already investigated in previous papers (Mason et al. 2003, Mouillot et al. 2005). These 4 trophic diversity indices were computed using $\mathrm{R}$ software ( $\mathrm{R}$ Development Core Team 2007).

Statistical analysis. Sampling points with fewer than 3 trophic levels in the assemblage were removed from statistical analysis. Indeed, with only 1 trophic level, trophic range, trophic evenness and trophic divergence do not make sense. For samples with only 2 species, $(S-1)^{-1}$ is equal to 1 , so the denominator of the FRO is 0 and the index is not defined. For assemblages with more than 2 species, but with only 2 trophic levels (i.e. some species have the same value of trophic level), there is only 1 PEW different from 0 and it is equal to 1 so that:

$$
\sum_{1=1}^{S-1} \min \left(\operatorname{PEW}_{1}, \frac{1}{S-1}\right)=\frac{1}{S-1}
$$

and FRO is always 0 .

The relationship between each of the 4 trophic diversity indices and abiotic parameters was estimated using a Bayesian model selection procedure for multiple linear regressions (function 'bicreg' of the BMA package under R software). This method is a Bayesianbased approach that quantifies the relative support of various models in the data (Johnson \& Omland 2004). The selection procedure was conducted using the BIC (Bayesian information criterion), and the inclusion of models in the final set was based on the analysis of Bayes factor (ratio of a model's posterior probabilities 
interpreted as the likelihood of one model versus another given the observed dataset; Burnham \& Anderson 2002).

A hierarchical classification using the Ward method (R package cluster) was carried out to classify the 37 stations into zones according to the values of 10 environmental parameters for the 12 mo of the present study. According to previous studies (Ramos Miranda et al. 2005a), 3 seasons were defined based on weather conditions (wind, rain and temperature): the dry season (February to May), the wet season (June to September) and the 'Nortes' season (October to January).

Analyses of variance (ANOVA) with 2 factors (zone, season and their interaction) were computed using the 4 trophic diversity indices (Table 1) and species richness as predicted variables.

For each pair of stations, we estimated dissimilarity between the 2 assemblages by using the Bray-Curtis index. We chose this index because it measures the 2 facets of biotic dissimilarity: species identity and species dominance.

Similarly for each pair of stations $(i, j)$ and for each trophic diversity index and species richness $\left(\operatorname{Ind}_{k}\right)$, we computed the distance $\operatorname{dInd}_{k}(i, j)$ to estimate the absolute relative difference in index values with:

$$
\operatorname{dInd}_{k}(i, j)=\frac{\left[2 \times\left\|\operatorname{Ind}_{k}(i)-\operatorname{Ind}_{k}(j)\right\|\right]}{\left[\operatorname{Ind}_{k}(i)+\operatorname{Ind}_{k}(j)\right]}
$$

Then, to test whether the biotic dissimilarity between 2 assemblages correlates with the dissimilarity of their trophic diversity, 6 Mantel's tests were computed (package 'ape' of R software) between the BrayCurtis dissimilarity matrix and each of the matrices containing a diversity dissimilarity (richness and 4 trophic diversity indices).

Given the geographical zones discriminated by the Ward classification and the a priori fixed seasons, we aggregated data for species abundance from corresponding stations into spatiotemporal strata. Species richness and trophic diversity indices were also estimated for each stratum. We then applied the same methodology as at the local scale to discover whether the dissimilarity in trophic diversity indices is related to the dissimilarity in species composition.

\section{RESULTS}

Among the 444 sampling points (37 stations $\times 12 \mathrm{mo}$ ), 132 were removed before statistical analysis because (1) environmental parameters were missing after technical problems (96 sampling points), or (2) the net was empty (11 sampling points), (3) we caught fewer than 3 different trophic levels which is the minimum needed to compute trophic diversity indices (28 sampling points).

In the 312 remaining samples, a total of 36744 nektonic organisms were caught for a total biomass of $\sim 600 \mathrm{~kg}$.

Total species richness was of 101 species: 83 teleosts, 5 elasmobranchs, 7 shrimp species (family Penaeidae), 4 crab species (genus Callinectes), 1 Mantis shrimp (Squilla empusa) and 1 squid (Lolliguncula brevis). Invertebrates (mainly shrimps and crabs) were often an important part of the biomass (mean \pm SD: $32.9 \pm$ $27.6 \%$ ). Their contribution to the total biomass of each nekton assemblage ranged from 0 to $100 \%$.

\section{Environmental parameters}

As expected, environmental variables showed large ranges of values. Water depth varied from 0.8 to $12.4 \mathrm{~m}$ with a mean $\pm \mathrm{SD}$ of $4.2 \pm 2.5 \mathrm{~m}$. Transparency values filled all the potential range (varying from 2 to $100 \%$ ), but the mean remained low $(15.7 \pm 14.7 \%)$. Similarly, surface salinity ranged from 0.2 to 40.5 PSU (mean $28 \pm$ $9.7 \mathrm{ppm}$ ) showing a gradient from euhaline to freshwater conditions. Water temperature was high $(27.8 \pm$ $2.6^{\circ} \mathrm{C}$ ) with extreme values of 22.5 and $32.5^{\circ} \mathrm{C}$ during the Nortes season and at the end of the dry season, respectively. The $\mathrm{pH}$ showed a large range of values from 5.05 to $8.94(7.74 \pm 0.72)$. Dissolved oxygen values varied from 1.5 to $9.8 \mathrm{mg} \mathrm{l}^{-1}$ with a mean value of $6.4 \pm$ $1.5 \mathrm{mg} \mathrm{l}^{-1}$.

As expected, given the low depth, physico-chemical parameters measured at the surface and at the bottom of the water column were highly correlated $(0.949$ for temperature, 0.860 for salinity, 0.966 for $\mathrm{pH}$ and 0.834 for dissolved oxygen). Furthermore, some environmental parameters were significantly correlated with one another, but Pearson coefficients of correlation remained low $(<0.57)$. For example, depth and salinity were positively correlated $(r=0.509$ for surface water and $r=0.555$ for bottom waters). Temperature and dissolved oxygen were globally negatively linked with a coefficient of correlation ranging from -0.466 to -0.569 for surface and bottom waters, respectively.

The hierarchical classification, based on environmental conditions, discriminated 3 main clusters (Fig. 3): one group (Coast 1) with Stns 1 to 12 corresponding to the coast between the mouth of the Usumacinta River and the mouth of the San Pablo y Pedro River (Fig. 1); a second group (Coast 2) with Stns 13 to 25 corresponding to the external edge of the Terminos lagoon; and a third group (Lagoon) with Stns 26 to 37 located in the southern part of the lagoon. In other words this classification based on environmental parameters matches the geography of the coast (Fig. 1). 


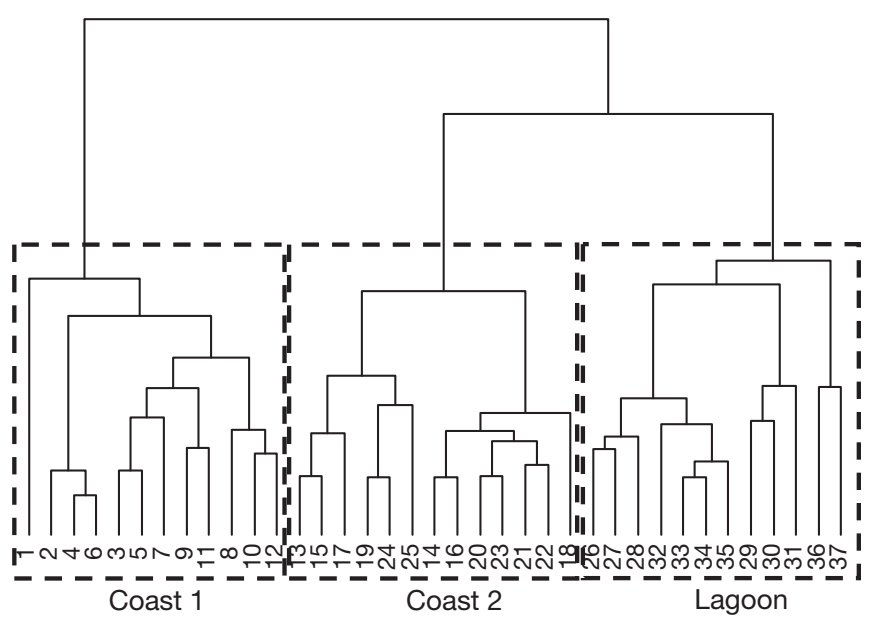

Fig. 3. Dendrogram of the 37 stations according to a Ward's classification based on 10 environmental parameters measured each month. Three zones corresponding to the 3 main clusters were named based on their position on the transect (Fig. 1)

\section{Environmental effects on trophic diversity indices}

Given the very strong correlations between physicochemical measures at the 2 layers (surface and bottom) of the water column, we used only bottom temperatures, salinities, $\mathrm{pH}$ and dissolved oxygen values for multiple regressions. Table 1 shows the results of the Bayesian model selection procedure carried out for the modeling of the 4 trophic diversity indices as a function of depth, transparency, bottom temperatures, salinities, $\mathrm{pH}$ and dissolved oxygen values. Very similar results were obtained using surface physico-chemical variables, but we do not present them for reasons of clarity. For each of the 4 indices, the evidence of the best model over the second-best (given by the Bayes factor) was always substantial, thus only 1 model was retained during the selection.
Only 3 out of 6 variables had an effect on the 4 indices: depth, transparency and bottom temperature. Furthermore, for each index, few environmental variables explained trophic diversity index variations. Water depth negatively influenced the number of trophic levels. The trophic range and the number of trophic levels were positively affected by the bottom temperature. Trophic divergence index was positively related to water depth and transparency. Only water depth influenced trophic evenness.

Overall, the linear models explained only between 3.8 and $15.7 \%$ of the total variation of nekton trophic diversity indices.

\section{Testing spatial and temporal effects on trophic diversity}

Table 2 shows the results of the ANOVAs carried out at the local scale (station). Spatial effect significantly influenced species richness and the number of trophic levels, with more species collected in stations within the lagoon than in stations situated outside. FD $_{\text {var }}$ varied significantly with the zone while the interaction between season and zone factors was significant. The 2 other indices (range and FRO) were unaffected by the 2 factors or by their interaction. Fig. 4 clearly shows the spatiotemporal consistency for these latter indices.

\section{Relations between species turnover and trophic diversity dissimilarities}

At the local scale (station), the mean \pm SD BrayCurtis dissimilarity index was $0.853 \pm 0.147$ between samples.

The Mantel tests showed positive significant correlations between Bray-Curtis dissimilarities and each of the 5 absolute relative differences for indices but with low Mantel correlation coefficients $(0.21$ for species richness and $<0.22$ for the 4 trophic diversity indices). This outcome means that even if the similarity between 2 communities significantly affects the similarity of their trophic structure, the effect remains weak.

With the 3 seasons and 3 geographical zones, 9 spatiotemporal strata were constructed from the 312 stations. At this regional scale the Bray-Curtis dissimilarity among strata dropped to $0.493 \pm 0.101$. For all trophic diversity indices, the Mantel tests showed no significant relationships between the 
Table 2. ANOVA $F$-values for the effect of spatial and temporal factors on 4 trophic diversity indices and species richness for $312 \mathrm{sam}$ pling points. The degree of freedom (df) of each factor is given at the head of the column. $\mathrm{FD}_{\mathrm{var}}=\mathrm{FD}_{\mathrm{var}}$ index of Mason et al. (2003); $\mathrm{FRO}=$ functional regularity index. ${ }^{\mathrm{ns}}$ non significant; ${ }^{*} \mathrm{p}<0.05$

$$
{ }^{* *} \mathrm{p}<0.01 ;{ }^{* * *} \mathrm{p}<0.001
$$

\begin{tabular}{|lccc|}
\hline Index & $\begin{array}{c}\text { Season } \\
(\mathrm{df}=2)\end{array}$ & $\begin{array}{c}\text { Zone } \\
(\mathrm{df}=2)\end{array}$ & $\begin{array}{c}\text { Zone } \times \text { Season } \\
(\mathrm{df}=4)\end{array}$ \\
\hline No. of species & $0.996^{\mathrm{ns}}$ & $6.348^{* *}$ & $2.147^{\mathrm{ns}}$ \\
No. of trophic levels & $2.501^{\mathrm{ns}}$ & $10.585^{* * *}$ & $2.049^{\mathrm{ns}}$ \\
Range of trophic levels & $1.394^{\mathrm{ns}}$ & $1.936^{\mathrm{ns}}$ & $1.287^{\mathrm{ns}}$ \\
FD $_{\text {var }}$ & $1.612^{\mathrm{ns}}$ & $3.437^{*}$ & $2.949^{*}$ \\
FRO & $1.951^{\mathrm{ns}}$ & $0.028^{\mathrm{ns}}$ & $0.415^{\mathrm{ns}}$ \\
\hline
\end{tabular}

indices and the species turnover in nekton species assemblages. As an illustration, Fig. 5 presents the trophic spectrum of the 9 spatiotemporal strata (regional scale), showing a global consistency for all indices despite species turnover, particularly between stations belonging to the wet and Nortes seasons.

\section{DISCUSSION}

Environmental conditions were highly variable in space and time among our sampling points, as expected from the freshwater influence in this coastal area. Indeed, environmental conditions range from freshwater (near the mouth of the streams) to marine water (near the northern part of Carmen Island) with many intermediate states in terms of salinity, transparency and water depth (from the inner lagoon to the adjacent coast). More generally, the whole area could be divided into 3 main zones according to environmental conditions, and these 3 zones are consistent with the global hydrology (influence of the streams, current flowing thought the lagoon and marine water entries) (Figs. 1 \& 3). In parallel, the nekton composition in terms of species abundances is also highly different among samples (Bray-Curtis ranging from 0.082 to 1 ) and among spatiotemporal strata (Bray-Curtis ranging from 0.234 to 0.666 ), highlighting the high species turnover in these estuarine environments (e.g. Wagner 1999). The present case study is thus ideal to seek potentially stable patterns in trophic structure because tropical estuarine ecosystems contain many species and are characterized by high variability for both biotic and abiotic variables.

The multiple regressions with environmental variables (Table 1) showed that only a few envi- ronmental parameters drive the trophic structure of nekton assemblages. Trophic richness is mainly influenced by depth and temperature. Divergence is affected by depth and transparency and evenness just by depth. However, and this is the key point, the overall weak predictive power of the multiple regressions (3.8 to $15.7 \%$ ) suggests that the trophic diversity of nekton assemblages is relatively stable along environmental gradients.

This result is confirmed by ANOVA tests showing that trophic range and trophic evenness are invariant across space and time (Fig. 4), while species richness and the number of trophic levels differ among zones. The findings suggest that even when changes occur in nektonic species richness, trophic diversity indices remain stable over space and time. More generally, Bray-Curtis dissimilarities between pairs of samples demonstrate the high turnover in the composition of nekton assemblages. The significant but weak correlations observed at the local scale between these assemblage dissimilarities and differences observed for trophic diversity indices do not
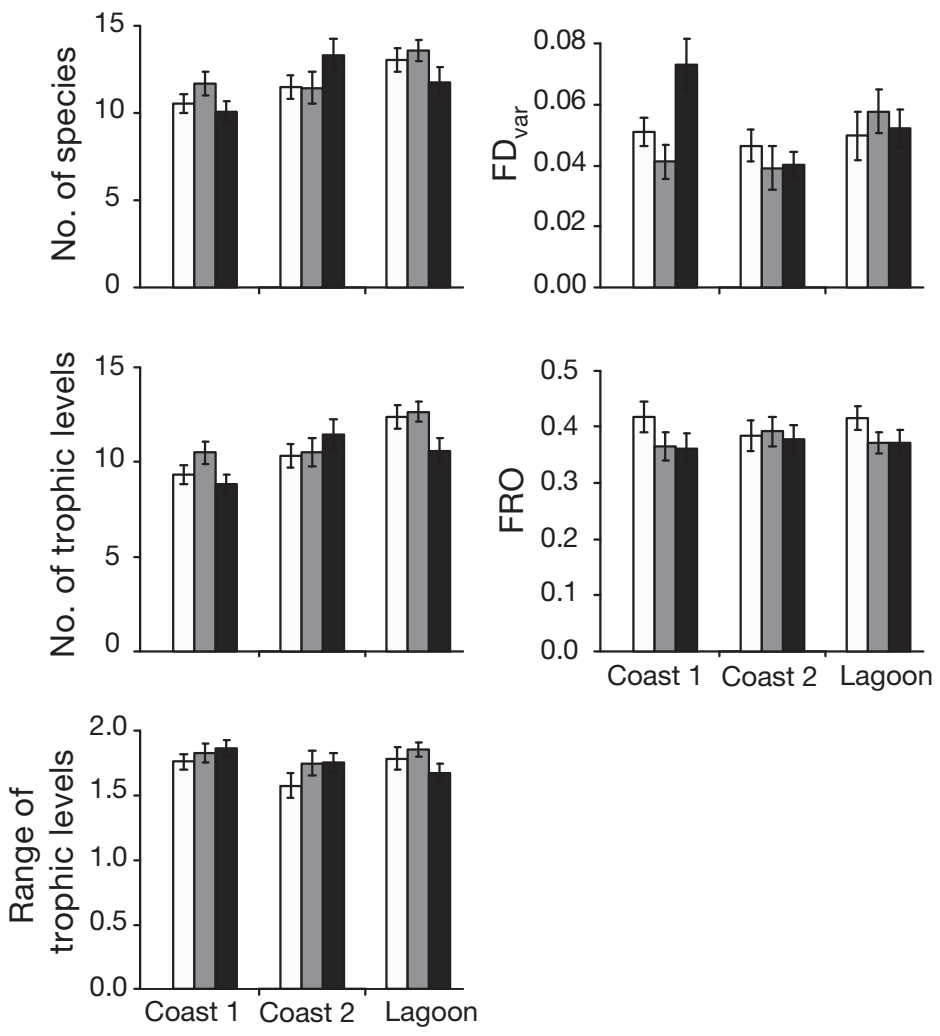

Fig. 4. Mean $( \pm \mathrm{SE})$ of species richness and of 4 trophic diversity indices estimated over areas (see Figs. 1 \& 3) and seasons. 'Dry' (white bars) corresponds to the period from February to May, 'wet' (grey bars) to June to September and 'Nortes' (black bars) to October to January. ANOVA tests are summarized in Table 2. $\mathrm{FD}_{\mathrm{var}}=\mathrm{FD}_{\mathrm{var}}$ index of Mason et al. (2003); FRO = functional regularity index 
Coast 1

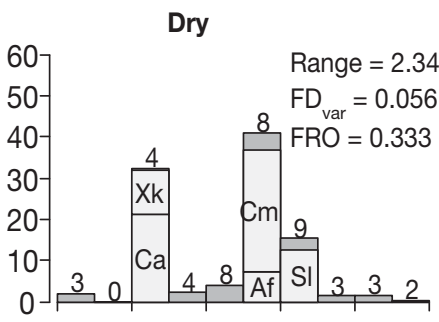

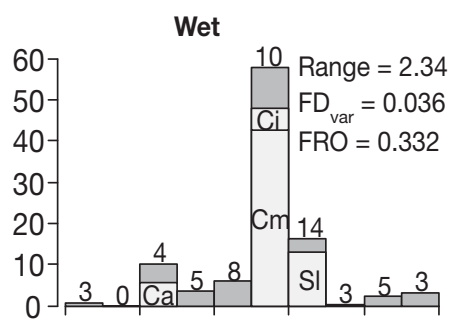
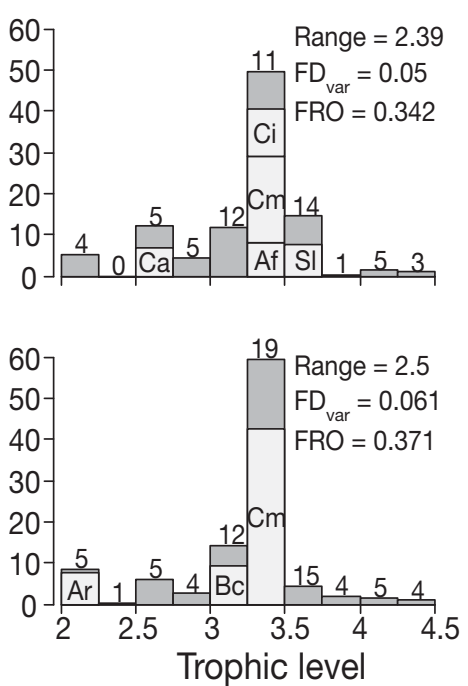
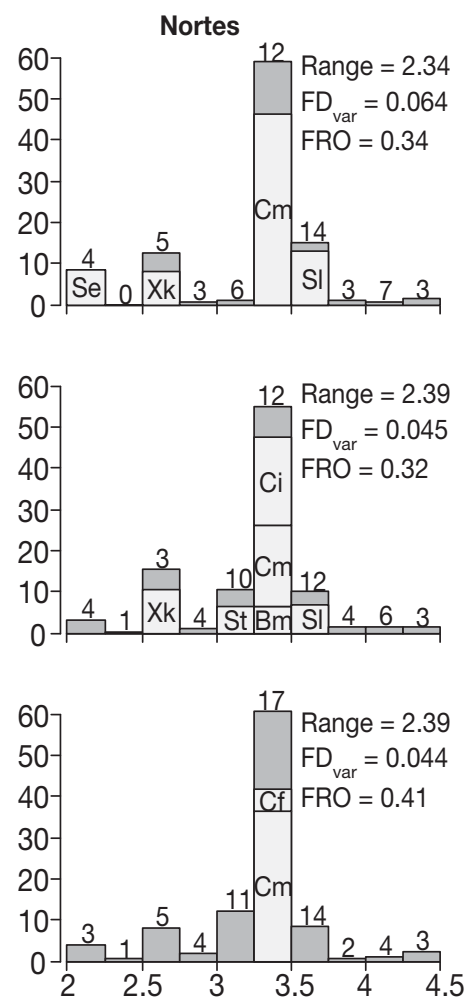

Fig. 5. Biomass distribution along the trophic level $(T L)$ axis for each of the 9 spatiotemporal strata. Ten classes of $T L$ were considered (each class has a width of 0.25 ). The values of the 3 trophic diversity indices are given for each stratum. For each class, the number of species is given at the top of the corresponding bar. The relative biomasses $>5 \%$ are represented by white rectangles, with the coded names of the species inside: Ariopsis felis (Af), Archosargus rhomboidalis (Ar), Bagre marinus (Bm), Bairdiella chrysoura (Bc), Callinectes sapidus (Ca), Callinectes similis (Ci), Cathorops melanopus (Cm), Chaetodipteurs faber (Cf), Dasyatis sabina (Ds), Sphoeroides testudineus (St), Squilla empusa (Se), Stellifer lanceolatus (Sl) and Xiphopenaeus kroyeri $(\mathrm{Xk})$

arise simply from strong similarities in assemblage compositions. In other words, although species composition differs among local assemblages, the trophic structure of nekton assemblages is rather similar.

In particular, the high species turnover holds also for dominant species (Table 3). Indeed, 14 different species were ranked among the top 3 in terms of biomass for more than $5 \%$ of the stations. Among these 14 species, 4 taxonomic groups of the 6 present at the regional scale were represented (Teleostii and 3 crustacean families: Penaeidae, Squillidae and Portunidae). Therefore, we can reject the hypothesis that our stable patterns at the local scale for trophic divergence and evenness result from the presence of a couple of ubiquitous and abundant species that may homogenize the trophic structure of nekton assemblages regardless of environment. For instance, the most abundant species over all the samples, the dark sea catfish Cathorops melanopus, was present in $60 \%$ of the stations but was among the 3 most abundant species in only $75 \%$ of these cases, or just $45 \%$ of the 312 stations. Conversely, the American stardrum
Stellifer lanceolatus was the most widespread species, present in $71 \%$ of the stations, but among the 3 dominant species in only $28 \%$ of the cases. The Western Atlantic seabream Archosargus rhomboidalis was globally scarce but was quite abundant when present.

Moreover, because all abundant species, except the Western Atlantic seabream and the mantis shrimp Squilla empusa, have relatively similar trophic levels (between 2.6 and 3.5); the biomass of nekton assemblages tended to peak at 3 in all the samples despite high species turnover. As a consequence, trophic evenness and trophic divergence indices, which describe the distribution of biomass along the trophic axis, tended to show stable patterns at the local scale (Fig. 4) with weak relationships to environmental variables.

Species turnover is also remarkable for the 2 extremities of the trophic chain (Table 4). For the minimum trophic level, 7 species (with trophic levels less than $2.7)$ contributed to $96 \%$ of the cases. As a result, in $64 \%$ of the stations studied, the minimum trophic level was consistently low (less than 2.3). Similarly, 4 species 
Table 3. List of dominant species for trophic diversity patterns at the local scale (i.e. over the 312 sampling points). Main taxonomic groups are given in parentheses: Fi = Fish (Teleosteii), $\mathrm{Cr}=\mathrm{Crab}$ (Portunidae), $\mathrm{Sh}=\mathrm{Shrimp}$ (Penaeidae), and Msh = Mantis shrimp (Squillidae). The percentage of occurrence is the proportion of stations in which the species was present. The values in the 4 last columns are the percentages of stations where the species was, respectively: the most abundant species (in terms of

biomass), the second-most abundant, the third-most abundant and, finally, where it was among the 3 dominant species

\begin{tabular}{|lccrrrr|}
\hline Taxon & Trophic level & \% occurrence & \% 1st & \% 2nd & \% 3rd & \% (1st, 2nd, or 3rd) \\
\hline Cathorops melanopus (Fi) & 3.35 & 58.97 & 28.85 & 9.94 & 6.09 & 44.88 \\
Callinectes sapidus (Cr) & 2.6 & 43.27 & 13.14 & 6.73 & 7.69 & 27.56 \\
Callinectes similis (Cr) & 3.3 & 46.47 & 9.94 & 6.41 & 7.05 & 23.40 \\
Xiphopenaeus kroyeri (Sh) & 2.7 & 58.97 & 9.62 & 8.01 & 8.33 & 25.96 \\
Stellifer lanceolatus (Fi) & 3.5 & 71.15 & 6.41 & 12.82 & 9.62 & 28.85 \\
Bairdiella chrysoura (Fi) & 3.2 & 33.33 & 4.81 & 4.17 & 2.24 & 11.22 \\
Archosargus rhomboidalis (Fi) & 2.22 & 12.82 & 3.53 & 3.85 & 2.88 & 10.26 \\
Bagre marinus (Fi) & 3.28 & 45.19 & 2.88 & 5.13 & 3.85 & 11.86 \\
Ariopsis felis (Fi) & 3.29 & 34.29 & 2.56 & 5.45 & 5.45 & 13.46 \\
Squilla empusa (Msh) & 2.2 & 35.90 & 2.24 & 4.17 & 2.56 & 8.97 \\
Sphoeroides testudineus (Fi) & 3.24 & 22.76 & 2.24 & 4.49 & 3.85 & 10.58 \\
Chaetodipterus faber (Fi) & 3.39 & 19.23 & 1.92 & 2.24 & 2.24 & 6.40 \\
Symphurus plagiusa (Fi) & 2.99 & 45.19 & 1.60 & 2.56 & 4.49 & 8.65 \\
Litopenaeus setiferus (Sh) & 2.7 & 50.64 & 0.32 & 2.88 & 2.56 & 5.76 \\
& & Total & 90.06 & 78.85 & 68.90 & \\
\hline
\end{tabular}

contributed to $64 \%$ of the maximum trophic level observed (16 for $90 \%$ ), with trophic levels greater than 4. As a consequence, locally, the trophic range was very consistent across space and time, ca. 1.7 to 1.8 , regardless of species composition and environmental conditions. In addition, some species with low (the crab Callinectes sapidus and the shrimp Xiphopenaeus kroyeri) or high trophic levels (the fishes Cynoscion arenarius and Cynoscion nothus) were ubiquitous enough to prevent the decrease of trophic chain length in all sampled assemblages. Indeed, these 4 species did not have the most extreme $T L$ values (the 2 low $T L$ values were $\sim 2.6$ and the 2 high $T L$ values were $\sim 4.1$ ), but when the species with the most extreme trophic level values were absent, these 4 widespread species prevented the trophic range from decreasing too much and played an insurance role in maintaining the trophic chain length. Thus, despite a high species turnover among nekton assemblages, we observed a stable trophic chain length attributable to a species replacement for either low or high trophic values or to the presence of some abundant and widespread species at the regional scale with both low and high trophic levels.

Compared to the local scale, the patterns that emerged at the regional scale were even more remarkable (Fig. 5). The histograms in Fig. 5 confirm the regional predominance of species with trophic levels 3.25: the class 3.25 to 3.5 consistently accounted for more than half of the total nekton biomass. More precisely, for all the strata belonging to the wet and Nortes seasons, the trophic class 3.25 to 3.5 accounted invariably for between 50 and $60 \%$ of the total biomass (in 5
Table 4. Species within extreme trophic levels as well as their occurrences and their percentages of presence at the most extreme trophic level in assemblages. Main taxonomic groups are given in parentheses: $\mathrm{Fi}=$ Fish (Teleosteii), $\mathrm{Cr}=\mathrm{Crab}$ (Portunidae), Sh $=$ Shrimp (Penaeidae), and Msh = Mantis shrimp (Squillidae)

\begin{tabular}{|lccc|}
\hline Taxon & $\begin{array}{c}\text { Trophic } \\
\text { level }\end{array}$ & $\begin{array}{c}\text { occur- } \\
\text { rence }\end{array}$ & $\begin{array}{c}\% \min \\
\text { or \% max }\end{array}$ \\
\hline Minimum trophic levels & & & \\
Squilla empusa (Msh) & 2.2 & 35.90 & 26.60 \\
Callinectes sapidus (Cr) & 2.6 & 43.27 & 18.27 \\
Cetengraulis edentulus (Fi) & 2.11 & 17.31 & 17.31 \\
Sicyonia brevirostris (Sh) & 2.2 & 12.82 & 10.58 \\
Archosargus rhomboidalis (Fi) & 2.22 & 12.82 & 9.62 \\
Litopenaeus setiferus (Sh) & 2.7 & 50.64 & 9.62 \\
Xiphopenaeus kroyeri (Sh) & 2.7 & 58.97 & 3.85 \\
Total & & & 95.85 \\
Maximum trophic levels & & & \\
Cynoscion arenarius (Fi) & 4.28 & 37.18 & 24.68 \\
Trichiurus lepturus (Fi) & 4.45 & 19.87 & 18.91 \\
Cynoscion nothus (Fi) & 4.04 & 27.56 & 10.58 \\
Synodus foetens (Fi) & 4.5 & 8.97 & 8.97 \\
Total & & & 63.14 \\
\hline
\end{tabular}

cases out of 6 , the value is very close to $60 \%$ ), which is not a trivial result. At this regional scale of observation, the contribution of the most abundant species Cathorops melanopus to the total biomass ranges from 14 to $46 \%$. Therefore, the peak of biomass between 3.25 and 3.5 was not always and solely due to the dark sea catfish but also to the swimming blue crab Callinectes similis ( $T L=3.3$ ) and to the hardhead sea catfish Ariopsis felis $(T L=3.29)$, with respective maxi- 
mum contributions of 20 and $8 \%$. Moreover, besides these dominant species, a lot of other species (8 to 19) contributed to the peak between 3.25 and 3.5.

Overall, the results obtained at the regional scale among the 9 spatiotemporal strata showed that variations in trophic diversity indices do not correlate with the rate of species turnover in nekton assemblages. For example, Nortes Coast 1 and Wet Coast 2 had a BrayCurtis index of 0.575 , but exhibited low differences in their trophic divergence and trophic evenness (Fig. 5). In other words, 2 very different assemblages (in terms of species composition and/or abundance) are as likely to have similar patterns of trophic diversity as are 2 assemblages with similar specific composition. These results suggest again that despite variations in species composition and abundances among strata, we observed a remarkably stable pattern in the trophic structure of nekton assemblages.

The composition of nektonic assemblages supports the need for taking into account all organisms without taxonomic considerations. Indeed, if we just consider fish, we have a bias in the nekton trophic diversity estimation because shrimps and crabs are abundant in this area and have low trophic levels compared to most fish species. For example, among the 12 lowest trophic levels, only 5 corresponded to fish species; among these, only 3 were abundant species. If shrimps and crabs had not been captured or considered in the present study, the base of the trophic chain would have been partially reduced and our conclusions about stable trophic structures would thus have been biased. For example, the swimming blue crab Callinectes sapidus and the shrimp Xiphopenaeus kroyeri constitute most of the biomass for the trophic class between 2.5 and 2.75 , which drives the trophic structure, especially for the 2 coastal zones during the dry season (Fig. 5).

The sampling method using a shrimp trawl is probably the best for estimating nekton trophic diversity because it is an active method and because the small mesh size allows capturing both fish and small invertebrates.

A limitation in the present study comes from the estimation of the trophic level. Coastal areas and more particularly coastal lagoons are marked by the presence of age classes from juveniles to adults, depending on species' reproductive strategies. Diet can change with growth, and even if the corresponding trophic levels are known, it is difficult to associate them correctly with each individual. Because the trophic level increases with body size for high trophic level species, we certainly overestimated the trophic level for small individuals of species at high trophic levels (such as Cynoscion sp.). Furthermore, in highly variable systems such as coastal zones, the diet of omnivorous macroorganisms is not homogeneous throughout the year, but follows migrations and seasons. In our data set, some species have similar values for trophic level: in total we had 101 species but only 66 different trophic level values. Because trophic level is a continuous trait ranging from 2 to 4.5 for heterotrophic organisms, the number of entities would be a priori synonymous with species richness. However, estimated trophic levels from the literature are sometimes provided at the level of the genus, with related species then being assigned the same trophic level value. This bias is not inherent in the trophic level concept but instead arises from the lack of data, underlining the difficulty of developing a large and complete database of many species for functional traits. Finally, despite these intrinsic and extrinsic biases due to the trophic level estimation, we still consider that this ecological trait has the advantage of providing a good approximation of the position of all nekton species along the trophic chain without any taxonomic limitation.

Many studies dealing with trophic interactions in aquatic systems elucidate 2 structuring forces (Leibold et al. 1997, Maciej Gliwicz 2002). When the amount of nutrient is the limiting factor, a bottom-up effect constrains the reproduction and growth of the lowest trophic levels and then limits the abundance of their predators (Ware \& Thomson 2005, Frederiksen et al. 2006). The maximum biomasses are thus at the lowest trophic levels. Conversely, when top predators are abundant they may have a top-down effect on their preys which themselves prey on species of lower trophic levels. The biomasses of species belonging to low trophic levels are under the control of the species within the highest trophic levels. In the present case study, none of these effects appeared to occur: we observed stable trophic structures centered around the middle of the trophic axis through space and time and along environmental gradients. Indeed, on the one hand, the 3 main streams carry a lot of organic matter and nutrients throughout the year and especially during the wet season when the freshwater discharge is high. This continuous flow may not limit the primary productivity and primary consumption in the ecosystem and thus may prevent the trophic structure from experiencing a bottom-up effect. On the other hand, as described previously, top predators (i.e. species with trophic levels higher than 4.0) are not as abundant in biomass compared to the potential biomass of preys, whatever the season or zone, and thus are unlikely to provoke a top-down effect. Humans, through fishery activities, may also modify trophic structure in species assemblages (Pauly et al. 1998). The only fishery in the Terminos Lagoon area is shrimp, primarily around the city of Ciudad del Carmen. The nets used are like the one we used for sampling. As explained previously, these small mesh nets are nonselective, and there are 
high quantities of bycatch (crabs and fishes). Therefore, we suppose that fishing similarly decreases the biomasses of all trophic levels and thus may not deeply modify the trophic structure of nekton assemblages.

We have found advantages to describing trophic diversity based on a set of indices that focuses on each of its 3 independent components; indeed, our indices summarized the shape of the Biomass Trophic Level Spectra proposed by Sosa-López et al. (2005). Using this promising approach, we have shown that the nekton assemblage trophic structure along the Terminos coast is unexpectedly stable despite strong environmental gradients that enhance species turnover in space and time. In turn, these results suggest that some deterministic ecological processes may shape the trophic structure of food webs, at least in nektonic coastal assemblages. A comparison with similar systems is now needed to confirm the relative invariance of trophic diversity along environmental gradients in estuarine ecosystems. Our results also show that researchers gain to consider all the organisms when seeking stable trophic patterns in assemblages because taxonomically different species may occupy the same trophic level and have the same impact on the food web. Such integrative approaches are implemented in Ecopath models to explore how biotic groups transfer matter through the ecosystem (e.g. Cruz-Escalona et al. 2007). The outputs of such models would contribute to the understanding of mechanisms underlying emergent properties of trophic structures.

Acknowledgements. We thank Luis Ayala Pérez and Francisco Gómez Criollo for their help during field work. This research project was financed by the CONACYT and the government of the Campeche state (FOMIX 2005 CAM-C01-04). This research was partly supported by a PICS programme (MEXAPICS) financed by the CNRS. Three anonymous reviewers provided very useful and constructive comments.

\section{LITERATURE CITED}

Basset A, Sabetta L, Fonnesu A, Mouillot D and others (2006) Typology in Mediterranean transitional waters: new challenges and perspectives. Aquat Conserv 16:441-455

Bersier LF, Sugihara G (1997) Scaling regions for food web properties. Proc Natl Acad Sci USA 94:1247-1251

Bersier LF, Dixon P, Sugihara G (1999) Scale invariant for scale-dependent behavior of the link density property in food webs: a matter of sampling effort? Am Nat 153: 676-682

Briand F, Cohen JE (1984) Community food webs have scaleinvariant structure. Nature 307:264-266

Burnham KP, Anderson DR (2002) Model selection and multimodel inference: a practical information-theoretic approach. Springer, New York

Castro-Aguirre JL (1978) Catalogo sistematico de los peces marinos que penetran a las aguas continentales de Mexico con aspectos zoogeograficos y ecologicos. Serie Científica Dir Gral Inst Nal Pesca, México
Costanza R, Darge R, Degroot R, Farber S, and others (1997) The value of the world's ecosystem services and natural capital. Nature 387:253-260

Cruz-Escalona VH, Arreguin-Sanchez F, Zetina-Rejon M (2007) Analysis of the ecosystem structure of Laguna Alvarado, western Gulf of Mexico, by means of a mass balance model. Estuar Coast Shelf Sci 72:155-167

David LT, Kjerfve B (1998) Tides and currents in a two-inlet coastal lagoon: Laguna de Terminos, Mexico. Cont Shelf Res 18:1057-1079

> Deb D (1995) Scale-dependence of food web structures: tropical ponds as paradigm. Oikos 72:245-262

> Diaz S, Fargione J, Chapin FS, Tilman D (2006) Biodiversity loss threatens human well-being. PLoS Biol 4:e277

Duffy JE, Cardinale BJ, France KE, McIntyre PB, Thébault E, Loreau M (2007) The functional role of biodiversity in ecosystems: incorporating trophic complexity. Ecol Lett 10:522-538

Fischer W (1978) Consultation on shrimp stocks in Caribbean and adjacent regions. FAO Fisheries Reports FIRD/R124, Vol I-VI, FAO, Rome

Frederiksen M, Edwards M, Richardson AJ, Halliday NC, Wanless S (2006) From plankton to top predators: bottomup control of a marine food web across four trophic levels. J Anim Ecol 75:1259-1268

Froese R, Pauly D (2000) FishBase 2000: concepts, design and data sources. ICLARM, Laguna

Froese R, Pauly D (2006) FishBase, available at www.fishbase.org

Gascuel D (2005) The trophic-level based model: a theoretical approach of fishing effects on marine ecosystems. Ecol Model 189:315-332

Grime JP (1998) Benefits of plant diversity to ecosystems: immediate, filter and founder effects. J Ecol 86:902-910

Havens K (1992) Scale and structure in natural food webs. Science 257:1107-1109

Holmlund CM, Hammer M (1999) Ecosystem services generated by fish populations. Ecol Econ 29:253-268

Hubbell SP (2001) The unified theory of biodiversity and biogegraphy. Princeton University Press, Princeton, NJ

> Johnson JB, Omland KS (2004) Model selection in ecology and evolution. Trends Ecol Evol 19:101-108

> Leibold MA, Chase JM, Shurin JB, Downing AL (1997) Species turnover and the regulation of trophic structure. Annu Rev Ecol Syst 28:467-494

- Maciej Gliwicz ZM (2002) On the different nature of topdown and bottom-up effects in pelagic food webs. Freshw Biol 47:2296-2312

> Martinez ND (1992) Constant connectance in community food webs. Am Nat 139:1208-1218

Martinez ND (1994) Scale-dependent constraints on food web structure. Am Nat 144:935-953

Mason NWH, MacGillivray K, Steel JB, Wilson JB (2003) An index of functional diversity. J Veg Sci 14:571-578

- Mason NWH, Mouillot D, Lee WG, Wilson JB (2005) Functional richness, functional evenness and functional divergence: the primary components of functional diversity. Oikos 111:112-118

> Mouillot D (2007) Niche-assembly vs. dispersal-assembly rules in coastal fish metacommunities: implications for a biodiversity management in brackish lagoons. J Appl Ecol 44:760-767

> Mouillot D, Mason NWH, Dumay O, Wilson JB (2005) Functional regularity: a neglected aspect of functional diversity. Oecologia 142:353-359

> Pauly D, Watson R (2005) Background and interpretation of the 'Marine Trophic Index' as a measure of biodiversity. 
Phil Trans R Soc Lond B 360:415-423

Pauly D, Christensen V, Dalsgaard J, Froese R, Torres F (1998) Fishing down marine food webs. Science 279: 860-863

Pauly D, Christensen V, Walters C (2000) Ecopath, ecosim, and ecospace as tools for evaluating ecosystem impact of fisheries. ICES J Mar Sci 57:697-706

Purvis A, Hector A (2000) Getting the measure of biodiversity. Nature 405:212-219

R Development Core Team (2007) R: a language and environment for statistical computing. R Foundation for Statistical Computing, Vienna, available at: www.R-project.org

Ramos Miranda JR, Mouillot D, Hernandez DF, Lopez AS, Do Chi T, Perez LA (2005a) Changes in four complementary facets of fish diversity in a tropical coastal lagoon after 18 years: a functional interpretation. Mar Ecol Prog Ser 304: $1-13$

Ramos-Miranda J, Quiniou L, Flores-Hernandez D, Do-Chi T, Ayala-Perez L, Sosa-Lopez A (2005b) Spatial and temporal

Editorial responsibility: Matthias Seaman,

Oldendorf/Luhe, Germany changes in the nekton of the Terminos Lagoon, Campeche, Mexico. J Fish Biol 66:513-530

Resendez Medina A (1981a) Estudio de los peces de la Laguna de Terminos, Campeche, Mexico, I. Biótica 6:239-291

Resendez Medina A (1981b) Estudio de los peces de la Laguna de Terminos, Campeche, Mexico, II. Biótica 6: $345-430$

Sosa-López A, Mouillot D, Chi TD, Ramos-Miranda J (2005) Ecological indicators based on fish biomass distribution along trophic levels: an application to the Terminos coastal lagoon, Mexico. ICES J Mar Sci 62:453-458

Sugihara G, Schoenly K, Trombla A (1989) Scale invariance in food web properties. Science 245:48-52

Wagner CM (1999) Expression of the estuarine species minimum in littoral fish assemblages of the lower Chesapeake Bay tributaries. Estuaries 22:304-312

Ware DM, Thomson RE (2005) Bottom-up ecosystem trophic dynamics determine fish production in the northeast. Pac Sci 308:1280-1284

Submitted: September 3, 2007; Accepted: February 22, 2008 Proofs received from author(s): July 9, 2008 